\title{
Urinary Iodide Excretion Measured with an Iodide-selective Ion Electrode : Studies on Normal Subjects of Varying Ages and Patients with Thyroid Diseases
}

\author{
Yukiko YABU ${ }^{1)}$, KiYoshi MIYAI ${ }^{1)}$, Yuichi ENDO ${ }^{1)}$, NaOShige HATA ${ }^{1)}$, \\ YASUSHI IIJIMA ${ }^{1)}$, SACHIKo HAYASHIZAKI ${ }^{1)}$, RYo FUSHIMI ${ }^{1)}$, \\ TOKuZo HARADA ${ }^{2)}$, OsAmu NOSE ${ }^{3)}$, AKIRA KOBAYASHI ${ }^{4}$, \\ FUMIO MATSUZUKA ${ }^{4)}$ AND KANJI KUMA
}

\author{
Department of Laboratory Medicine, the Central Laboratories for Clinical \\ Investigation $^{1)}$ and Department of Pediatrics ${ }^{3)}$, Osaka University \\ Medical School, Osaka, Itami Hospital ${ }^{2)}$, Itami and \\ Kuma Hospital ${ }^{4)}$, Kobe Japan
}

\begin{abstract}
As a part of studies concerning clinical application of the measurement of urinary iodide with an iodide-selective ion electrode, we report here the reference values for the iodide content or concentration in morning spot urine specimens from normal subjects of varying ages and studies with patients with thyroid diseases in Japan. The number distribution of the iodide content or concentration in the morning specimens appeared logarithmic normal in adults, children and infants. Normal ranges found in 95 per cent of populations of healthy subjects were 5.3 to $62.0 \mu$ moles $/ \mathrm{g}$ Creatinine $(\mathrm{Cr})$ for adults, 5.3 to $42 \mu \mathrm{moles} / \mathrm{g} \mathrm{Cr}$ for children, and 1.9 to $56 \mu \mathrm{M}$ for infants, respectively. Urinary iodide concentrations in breast-fed infants varied widely compared with those in bottle-fed infants. Mean values were $16.4 \mu \mathrm{M}$ for breast-fed infants and $8.6 \mu \mathrm{M}$ for bottle-fed infants, and they were not statistically different. Urine samples from the infants with transient hypothyroidism, who had undergone amniofetography showed extraordinarily high iodide concentrations, even though they were measured at 20th, 29th and 30th days after birth. Although urinary iodide excretion in patients with simple goiter was within normal limits, the mean was statistically lower than that in normal controls $(p<0.001)$. Because of the simplicity and rapidlity of the electrode method, we strongly recommend it for use in examining iodide excretion in patients with various thyroid diseases.
\end{abstract}

Received October 13, 1987

Correspondence should be addressed to Dr.

YUKIKO YABU, Department of Laboratory

Medicine, Osaka University Medical School,

Osaka 553 Japan.

This study was financially supported by a Research Grant-in-Aid from the Ministry of Education, Science and Culture, Japan.
Although iodine deficiency is no longer a major world health problem, thyroid dysfunction associated with therapeutic and diagnostic iodine administration has been reported with increasing frequency (Blum et al., 1974 ; Savoie et al., 1975 ; Rodesch et al., 1976; Theodoropoulos et al., 1979 ; 
Eason et al., 1984 ; Leger et al., 1984). In these cases, measurement of urinary iodide is necessary for diagnosis and treatment, because urinary excretion of iodide is the most valid index of iodine intake.

The classic chemical procedures for measurement of iodine are tedious, timeconsuming and sometimes inaccurate at low levels of iodine, and collecting urine for a 24 hour period is obviously incovenient for patients. Recently, we developed a simple and rapid method to measure iodide in urine with an iodide-selective ion electrode, and showed the usefulness of this electrode method as a laboratory procedure. We have also reported a good correlation between iodide concentrations in morning spot urine specimens and those collected over a 24 hour period (Yabu et al., 1986). In this manuscript, studies on iodide concentrations in urine measured with the electrode method on normal subjects of varying ages and patients with thyroid diseases are described. Clinical application to the measurement of urinary iodide is also discussed.

\section{Materials and Methods}

\section{Subjects and Specimens}

Urine specimens from 127 normal adults (39 men and 88 women, aged from 18 to 57 ), 43 normal children ( 27 boys and 16 girls, aged 3 to 10 ) and 30 infants (18 males and 12 females) were studied. All of them were healthy and none had goiter on careful palpation by either internists or pediatricians. Of 30 infants, 23 were fed with breast milk and 7 were with market milk, respectively. Urine samples from 3 neonates after amniofetography, and 24 patients with simple goiter (all women, aged from 11 to 32) were also examined. These 3 neonates were the patients recalled from the screening program for congenital hypothyroidism, and showed at least one of the clinical features of hypothyroidism, skin mottling, enlarged tongue or hypotonia. The diagnosis of simple goiter was made on finding a small, soft and diffuse goiter associated with euthyroidism, that was assessed from serum concentrations of thyroxine $\left(\mathrm{T}_{4}\right)$, triiodothyronine $\left(\mathrm{T}_{3}\right)$ and thyrotrophin (TSH), and $\mathrm{T}_{3}$ uptake test $\left(\mathrm{T}_{3} \mathrm{U}\right)$. None of them showed positive thyroidal autoantibodies (anti-thyroglobulin and anti-microsomal antibodies). Urinary iodide excretion in a patient with goitrous hypothyroidism without anti-thyroidal autoantibodies was also examined. She was a 55-year-old female who had been treated with $60 \mathrm{mg}$ of oxapium iodide (Esperan $\left.{ }^{\circledR}\right)$, an anti-cholinergic drug, for approximately 2 years.

Morning spot urine from the first urination before breakfast was examined in adults and children, and spot urine in the morning in infants and neonates. Three neonates who had undergone amniofetography were examined on the 20th, 29th and 30th days after birth, respectively. Urine samples from adults and children were usually taken on a habitual diet. In order to see serial changes in urinary iodide excretion on an unrestricted and a low iodine diet, urine specimens were taken from 9 normal adults every morning over a period of 2 weeks. Two to three specimens were taken from each individual patient with simple goiter over a one week period on an unrestricted habitual diet. All samples were stored at $-20^{\circ} \mathrm{C}$ with tight stoppers until used.

\section{Methods}

Urinary iodide concentrations were measured with an iodide-selective ion electrode (IodideSelectrode ${ }^{\circledR}$, Radiometer, Copenhagen, Denmark) and concentrations of urinary creatinine $(\mathrm{Cr})$ were measured by the Jaffe's rate method with an autoanalyzer as described previously (Yabu et al., 1986). Urinary iodide content was expressed as moles of iodide per gram of $\mathrm{Cr}$ times 1.0 (females) or 1.7 (males) in adults, according to the formula reported by Vought et al. (1963). In pre-adolescent children, iodine intake was assessed by moles of iodide per gram of $\mathrm{Cr}$ in both boys and girls (Clark et al., 1951) and by only iodide concentrations in infants, since $\mathrm{Cr}$ excretion in infants is much lower than that in later life (Applegarth et al., 1968) and renal function is not sufficient until the age of 1-2 years (Rubin et al., 1949). Serum concentrations of thyroid hormones and TSH were measured with conventional radioimmunoassay kits, and anti-thyroidal autoantibodies were with SeroidaAMC and ATD kits (Fujirebio Inc, Tokyo), respec- 
tively. Statistical analyses were performed by the Mann-Whitney U test.

\section{Results}

Iodide content in morning spot urine

Fig. 1 shows the number distribution of iodide content in morning spot urine specimens from normal adults and children. Both appeared typical logarithmic normal distributions. Normal ranges found in 95 per cent of populations of healthy subjects were 5.3 to 62.0 with a mean of 23.8 $\mu$ moles/g $\mathrm{Cr}$ in adults and 5.3 to 42.0 with a mean of $21.7 \mu$ moles/g $\mathrm{Cr}$ in children, respectively. There was no statistical difference in the urinary iodide content

\section{ADULTS}

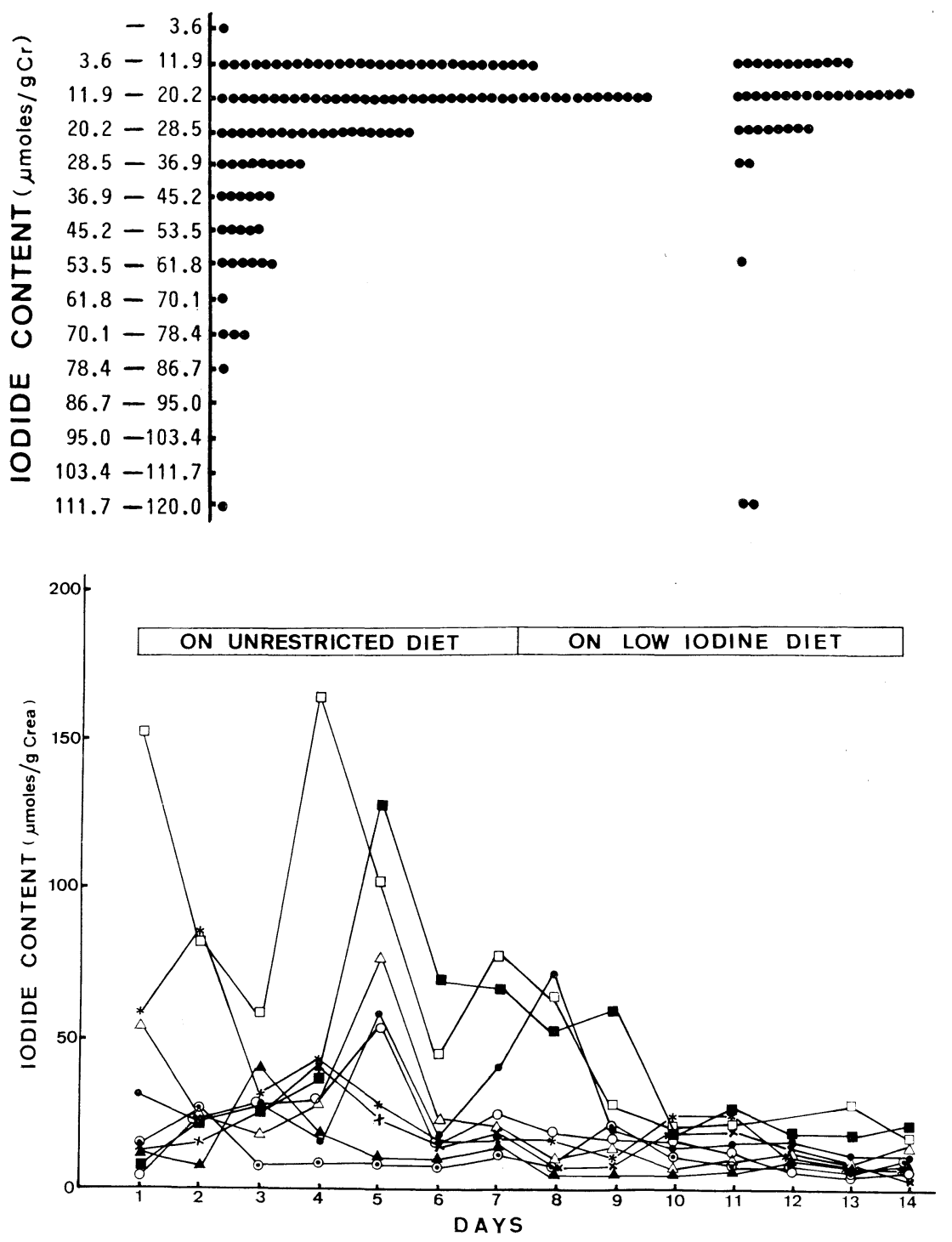

Fig. 1. Iodide content in morning spot urine specimens from healthy adults and children. All of them were taken on a habitual unrestricted diet.
Fig. 2. Daily iodide excretion on an unrestricted and a low iodine diet. Samples were taken from 9 normal healthy adults every morning for a week on an unrestricted diet and for the next week on a low iodine diet. 
in adults and children.

\section{Daily change in iodide excretion on unrestricted and low iodine diet}

As shown in Fig. 2, iodide content in urine samples from 9 normal volunteers on an unrestricted diet fluctuated according to iodine intake in food. On a low iodine diet, the iodide content in urine decreased by the 3rd day and persisted at a low level without fluctuation. The mean $( \pm S D)$ iodide content in morning specimens on an unrestricted diet was $37.6 \pm 33.4 \mu \mathrm{moles} / \mathrm{g}$ $\mathrm{Cr}$ (number of samples $=63$ ) from 9 normal volunteers over a week, and it decreased to $11.3 \pm 5.3 \mu \mathrm{moles} / \mathrm{g} \mathrm{Cr}$ (number of samples $=9$ ), after iodine depletion for 6 days.

\section{Iodide excretion in infants}

The number distribution of the iodide concentration in urine specimens from 30 infants also appeared logarithmic normal (data not shown). The normal range found in 95 per cent of the popu- lation was 1.9 to $56 \mu \mathrm{M}$ with a mean of 14.6 $\mu \mathrm{M}$. As shown in Fig. 3, the urinary iodide concentration in infants fed with breast milk varied between 4.1 and $41.1 \mu \mathrm{M}$ with a mean of $16.4 \mu \mathrm{M}$, and in infants

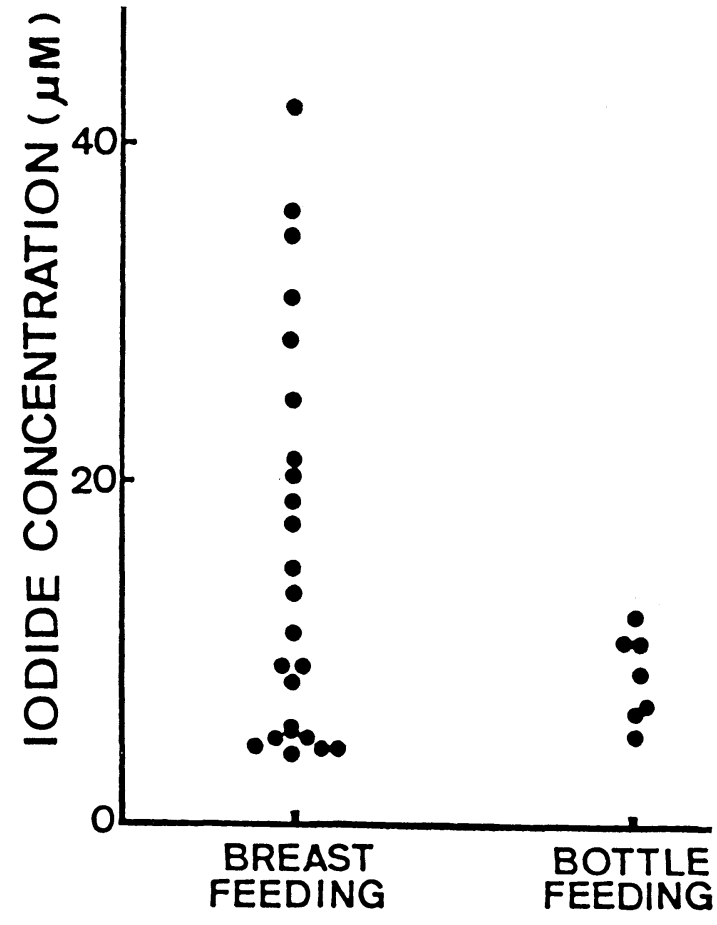

Fig. 3. The number distribution of iodide concentration in breast-fed and bottle-fed infants. The mean values in the two groups were not statistically different.

Table 1. Thyroid function tests and urinary iodide concentrations in 3 neonates with transient hypothyroidism

\begin{tabular}{lccccccc}
\hline & age/sex & $\begin{array}{c}\mathrm{T}_{4} \\
(\mu \mathrm{g} / \mathrm{dl})\end{array}$ & $\begin{array}{c}\mathrm{T}_{3} \mathrm{U} \\
(\%)\end{array}$ & $\begin{array}{c}\mathrm{T}_{3} \\
(\mathrm{ng} / \mathrm{dl})\end{array}$ & $\begin{array}{c}\mathrm{TSH} \\
(\mu \mathrm{U} / \mathrm{ml})\end{array}$ & $\begin{array}{c}\text { Thyroidal } \\
\text { autoantibodies }\end{array}$ & $\begin{array}{c}\text { iodide concen- } \\
\text { trations }(\mu \mathrm{M})\end{array}$ \\
\hline Case 1 & 16 days/F & 1.4 & 25.5 & 94 & $>160$ & $\begin{array}{c}\text { TG }(-) \\
\text { MC }(-)\end{array}$ & 675.4 \\
Case 2 & 24 days/M & 2.1 & 28.5 & 186 & 91.3 & $\begin{array}{c}\text { TG }(-) \\
\text { MC (-) }\end{array}$ & 57.2 \\
Case 3 & 15 days/F & 2.5 & n.d. & 96 & 264.3 & $\begin{array}{c}\text { TG }(-) \\
\text { MC (-) }\end{array}$ & 174.3 \\
\hline
\end{tabular}

TG denotes anti-thyroglobulin antibodies, MC anti-microsomal antibodies. The urinary iodide concentration was examined on the 30th day for case 1, the 20th day for case 2 and the 29th day for case 3 , respectively. n. d., not determined.

Normal ranges for infants (around a month old) in our laboratory are following: $T_{4}: 7.2-$ $14.8 \mu \mathrm{g} / \mathrm{dl}, \mathrm{T}_{3}: 163-283 \mathrm{ng} / \mathrm{dl}$ and $\mathrm{TSH}: 2.9-12.1 \mu \mathrm{U} / \mathrm{ml}$, respectively. $\mathrm{T}_{3} \mathrm{U}$ value for infants was not obtained. Refere the normal range for adults $(25.7-33.5 \%)$. 
NORMAL

CONTROLS

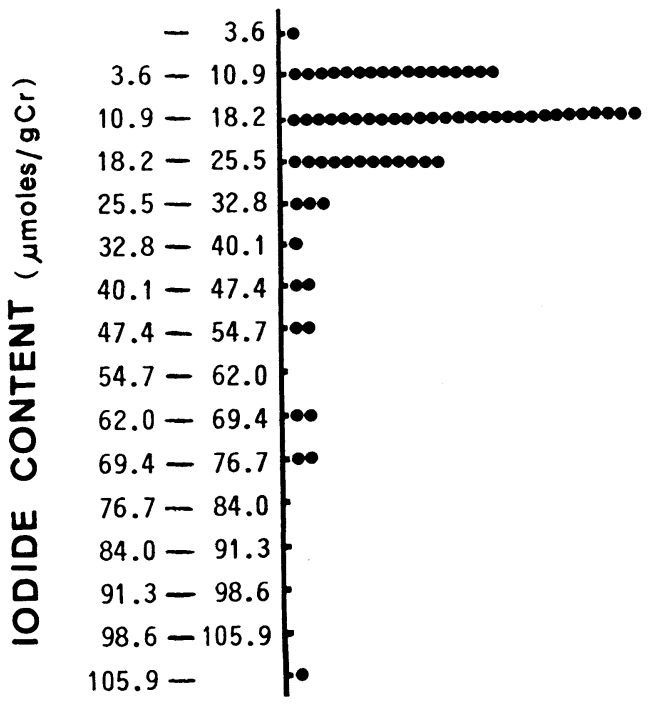

fed with market milk there was a very narrow distribution between 4.7 and $12.1 \mu \mathrm{M}$ with a mean of $8.6 \mu \mathrm{M}$. However, the mean values in the two groups were not statistically different. Three urine samples from the infants who had undergone amniofetography showed an extraordinarily high iodide concentration, 57.2, 174.3 and $675 \mu \mathrm{M}$, respectively. Their thyroid function tests at the time of re-call are summarized in Table 1. After the diagnosis of hypothyroidism, they were treated with levothyroxine. The replacement therapy was discontinued after certain periods, because their thyroid function tests returned to normal.

\section{Iodide excretion in patients with simple goiter}

Fifty-five urine specimens from 24 young female patients with simple goiter were compared with those from age and sex matched controls who were 73 normal healthy young females, aged 18 to 27 . As shown in Fig. 4, the iodide content in morning specimens from patients with simple
SIMPLE

\section{GOITER}

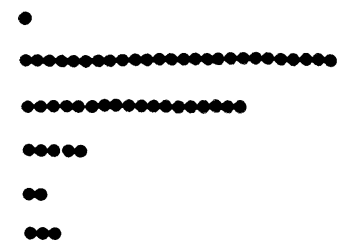

Fig. 4. Iodide content in morning spot urine specimens from normal controls and patients with simple goiter. Mean ages were $19.0 \pm 1.4$ years for normal controls and $18.4 \pm 6.4$ years for the patients, respectively. goiter (mean : $13.4 \mu$ moles/g $\mathrm{Cr}$ ) was statistically lower than in normal controls (mean : $22.4 \mu$ moles/g Cr) $(\mathrm{p}<0.001)$.

\section{Iodide excretion in a patient treated} with oxapium iodide

Three urine specimens obtained from a patient with goitrous hypothyroidism contained almost identical amounts of iodide i. e. $159.9,154.0$ aud $151.4 \mu$ moles/g Cr, which were about seven times the mean value for normal controls. She had a prominent goiter, $6.5 \mathrm{~cm}$ in transverse width and increased TSH $(16.4 \mu \mathrm{U} / \mathrm{ml}$, normal range : $0.3-6.5 \mu \mathrm{U} / \mathrm{ml})$. After discontinuation of the drug for 6 months, the goiter has disappeared in association with normal TSH. The urinary iodide excretion on her habitual diet ranged from 17.7 to 29.1 $\mu$ moles/g Cr.

\section{Discussion}

As a part of a series of studies on clinical application of the measurement of 
iodide in urine, we here describe the reference values for iodide content in morning spot urine speciments from normal subjects at various ages and studies of patients with thyroid diseases in Japan. The number distribution of urinary iodide content or concentration in specimens from normal adults, children and infants appeared logarithmic normal and there was no statistical difference between adults and children. On unrestricted habitual diet, urinary iodide content fluctuated according to iodine intake, as shown in Fig. 2. Therefore, frequent sampling should be done to estimate the iodide intake in each individual.

Since 1940 when Parmelee et al., (1940) reported 3 cases of newborn infants with goiter, it has been said that maternal intake of excess iodine is one of the causes of congenital goiter and hypothyroidism (Hassan et al., 1968 ; Carswell et al., 1970). Therefore, we had been concerned that breastfed infants in Japan might be exposed to much higher levels of iodine than bottlefed infants, since a large amount of seaweed is often ingested by mothers on their habitual diet, and iodide from food is actively transported into breast milk (Vorherr, 1974 ; Colett et al., 1984). However, studies in infants revealed that the urinary iodide concentration was not significantly different in breast-fed and bottle-fed groups, although samples from breast-fed infants varied over a wide range. It is noteworthy that the urinary iodide concentration of 3 infants after amniofetography was extraordinarily high, even though it was measured on the 20th, 29th and 30th days after birth. Recently, 2 cases of transient neonatal hypothyroidism caused by maternal ingestion of excess seaweed have been reported (Tohoya et al., 1987; Sakaguchi et $a l$, , 1987). Because iodide-induced transient hypothyroidism requires neither extensive examinations nor life-long thyroid hormone therapy, we believe that it is worth measuring the urinary iodide con- centration in neonates and their mothers, who showed increased TSH on the screening program.

It has been accepted worldwide that iodine deficiency is a major factor contributing to endemic goiter. Iodine excess has also been a cause of endemic goiter in Hokkaido (Suzuki et al., 1965). And both iodine deficiency and excess have been reported to contribute to sporadic, nontoxic goiter (Agerback et al., 1974; Trowbridge 1975). It is therefore interesting to examine the urinary iodide excretion in patients with simple goiter in Japan, where a large amount of iodine is taken in the habitual diet. Unexpectedly, the urinary iodide excretion in patients with simple goiter was within the normal range, but rather lower than that in normal controls $(p<0.001)$. Obviously this result does not mean that relative deficiency of iodine contributes to simple goiter in Japan, since the administration of iodine for 3 to 6 months did not cause the disappearance of goiter in those patients although it was done in only a few cases. It is possible to say, however, that excess iodine does not mainly contribute to sporadic simple goiter in Japan. Other factors including growth stimulators of immune origin might play an essential role in the development of goiter in these patients (Drexhange et al., 1980 ; Valente et al., 1983).

More than 50 kinds of drugs containing iodide are now widely used for diagnosis or therapy in Japan. Most of them are iodinated contrast media, which have been reported to cause goiter or thyroid dysfunction (Blum et al., 1974; Rodesch et al., 1976). Oxapium iodide contains $2.7 \mathrm{mg}$ of iodide per $10 \mathrm{mg}$, and $16.2 \mathrm{mg}$ of iodide had been administrated to the patient for approximately 2 years. Mild hypothyroidism and goiter were obviously produced by this medicine, since her goiter has disappeared after discontinuation of the medicine, and TSH returned to normal. This type of 
goitrous hypothyroidism might be very difficult to diagnose, since oxapium iodide itself is not a common drug which produces goiter and hypothyroidism, and the patient did not have an episode of excess iodine ingestion from food.

It is generally accepted that thyroid diseases in Japan have certain characteristic clinical features (Nagataki, 1970), although relationship between these features and excess iodine intake has not yet been revealed. And recently Yoshinari et al., (1983) and Tajiri et al. (1986) reported that more than half of patients with primary hypothyroidism who had goiter and normal thyroidal radioactive iodine uptake became euthyroid spontaneously after dietary iodine restriction. Thyroid dysfunction associated with iodine intake seems to be more common than had been expected. We therefore strongly recommend the measurement of the iodide content in morning spot urine as a routine examination by the simple electrode method.

\section{Acknowledgements}

We thank Drs. Y. Fukuda, K. Miki, N. Amino, K. Ichihara, C. Hayashi and K. Kohoda for valuable advice; Ms. S. Yamada and Ms. N. Yokota for secretarial assistance; and Ms. F. Oka, Ms. K. Tsujimura and Ms. T. Hiya for generous help as volunteers.

\section{References}

Applegarth, D. A., D. F. Hordwick and P. M. Ross (1968). Creatinine excretion in children and the usefulness of creatinine equivalents in amino acid chromatography. Clin. Chim. Acta 22, 131-134.

Agerback, H. and S. E. Jensen (1974). Quantitative studies of iodine metabolism in sporadic, non-toxic goiter. An evaluation of pathogenesis. Acta Endocrinol. 76, 67-73.

Blum, M., U. Weinberg, L. Shenkman and C. S. Hollander (1974). Hyperthyroidism after iodinated contrast medium. [N. Engl. J. Med. 291, 24-25.

Carswell, F., M. M. Kerr and J. H. Hutchinson (1970). Congenital goiter and hypothyroidism produced by maternal ingestion of iodides. Lancet i, 1241-1243.

Clark, L. C., H. L. Thompson, E. I. Beck and W. Jacobson (1951). Excretion of creatine and creatinine by children. Am. J. Dis. Child 81, 774-783.

Drexhage, H. A., G. F. Bottazzo and D. Doniach (1980). Evidence for thyroid-growth-stimulating immunoglobulins in some goitrous thyroid diseases. Lancet ii, 287-291.

Eason, R. J., M. S. Croxson, T. M. T. Lim, M. C. Evans and G. J. S. Cooper (1984). Goitre and thyroid dysfunction during chronic amiodarone treatment. N. Z. Med. J. 97, 216-219.

Frey, H. M. M., B. Rosenlund and J. P. Torgersen (1973). Value of single urine specimens in estimation of 24 hour urine iodine excretion. Acta Endocrinol. 72, 287-292.

Gushurst, C. A., J. A. Mueller, J. A. Green and F. Sedor (1984). Breast milk iodide: Reassessment in the 1980s. Pediatrics 73, 354357.

Hassan, A. I., G. H. Aref and S. Kassen (1968). Congenital iodine-induced goiter with hypothyroidism. Arch. Dis. Childh. 43, 702-704.

Leger, A. F., J. P. Massin, M. F. Laurent, M. Vincens, M. Auriol, O. B. Helal, G. Chomette and J. C. Savoie (1984). Iodine-induced thyrotoxicosis: analysis of eighty-five consecutive cases. Eur. J. Clin. Invest. 14, 449455.

Nagataki, S. (1970). Thyroid function in normal Japanese with special reference to iodine intake. Igaku no Ayumi 72, 621-628 (in Japanese).

Parmelee, A. H., E. Allen, I. F. Stein and H. Buxbaum (1940). Three cases of congenital goiter. Am. J. Obstet. Gynec. 40, 145-147.

Rodesch, F., M. Camus, A. M. Ermans, J. Dodion and F. Delange (1976). Adverse effect of amniofetography on fetal thyroid function. Am. J. Obstet. Gynecol. 126, 723-726.

Rubin, M. I., E. Bruck and M. Rapoport (1949). Maturation of renal function in childhood: Clearance studies. J. Clin. Invest. 28, 11441162.

Sakaguchi, C., N. Shintaku, H. Taneda, T. Ishigami, T. Okuno, Y. Takahashi, K. Akaishi, T. Yakura and S. Hamada (1987). A case 
of transient neonatal hypothyroidism caused by maternal ingestion of excess seaweed. Proceedings of the 21 th annual meeting for pediatric endocrinology, Chiba City, October 23-24, p. 105 (abstract, in Japanese).

Savoie, J. C., J. P. Massin, P. Thomopoulos and F. Leger (1975). Iodine-induced thyrotoxicosis in apparently normal thyroid glands. J. Clin. Endocrinol. Metab. 41, 685-691.

Suzuki, H., T. Higuchi, K. Sawa, S. Ohtaki and Y. Horiuchi (1965). Endemic coast goiter in Hokkaido, Japan. Acta Endocrinol. 50, 161176.

Tajiri, J., K. Higashi, M. Morita, T. Umeda and T. Sato (1986). Studies of hypothyroidism in patients with high iodine intake. J. Clin. Endocrinol Metab. 63, 412-417.

Theodoropoulos, T., L. E. Braverman and A. G. Vagenakis (1979). Iodine-induced hypothyroidism: A potential hazard during perinatal life. Science 205, 502-503.

Tohoya K., H. Ogawa and Y. Igarashi (1987). A case of transient neonatal hypothyroidism possibly induced by maternal ingestion of excess iodine. Hormone and Clinical Endocrinology (Hormone to Rinsho, in Japanese), Case Presentation 9, 131-133.
Trowbridge, F. L., J. Matovinovic, G. D. McLaren and M. Z. Nichaman (1975). Iodine and goiter in children. Pediatrics 56, 82-90. Valente, W. A., P. Vitti, C. M. Rotella, M. M. Vaughan, S. M. Aloj, E. F. Grollman, F. S. Ambesi-Impiobato and L. D. Kohn (1983). Antibodies that promote thyroid growth. A distinct population of thyroid-stimulating autoantibodies. N. Engl. J. Med. 309, 1028-1034.

Vorherr, H. (1974). Drug excretion in breast milk. Postgrad. Med. 56, 97-104.

Vought, R. L., W. T. London, L. Lutwak and T. D. Dublin (1963). Reliability of estimates of serum inorganic iodine and daily fecal and urinary iodine excretion from single casual specimens. J. Clin. Endocrinol. Metab. 23, 1218-1228.

Yabu, Y., K. Miyai, S. Hayashizaki, Y. Endo, N. Hata, Y. Iijima and R. Fushimi (1986). Measurement of iodide in urine using the iodide-selective ion electrode. Endocrinol. Japon. 33, 905-911.

Yoshinari, M., K. Okamura, T. Tokuyama, A. Shiroozu, T. Nakashima, K. Inoue and T. Omae (1983). Clinical importance of reversibility in primary goitrous hypothyroidism. Br. Med. J. 287. 720-722. 